\title{
Insulin in ischaemic heart disease: are associations explained by triglyceride concentrations? The Caerphilly prospective study
}

\author{
J W G Yarnell, P M Sweetnam, V Marks, J D Teale, C H Bolton
}

\section{Abstract}

Objective-To investigate the predictive value of fasting insulin concentrations for subsequent fatal or non-fatal ischaemic heart disease at five year follow up and to examine the associations between insulin and other indicators of risk.

Design-A prospective population study among 2512 men aged 45 to 59 at recruitment.

Setting-A whole population sample of men resident in Caerphilly, South Wales. Measurements-At recruitment fasting blood samples were taken for measurement of plasma lipids and serum insulin. Men were re-examined at a five year follow up and ischaemic heart disease events during this period were assessed from hospital notes, death certificates, and electrocardiograms.

Main results-Diabetic men and those men with a fasting blood glucose of $\geqslant 8$ mmol/1 were excluded from all analyses. In a univariate analysis the incidence of ischaemic heart disease increased with increasing concentration of fasting insulin, such that for men in the top $20 \%$ of the insulin distribution the odds of developing ischaemic heart disease were 1.87 relative to men in the bottom $20 \%$. On multivariate analysis this relation disappeared on adjusting for plasma triglycerides, body mass index, and evidence of ischaemic heart disease at recruitment.

Conclusion-In this population in South Wales there was no evidence that the fasting insulin concentration is an independent risk factor for ischaemic heart disease. The univariate association between insulin and incident disease was almost entirely explained by the association of both with triglycerides and body mass index.

(Br Heart f 1994;71:293-296)

Established risk factors for ischaemic heart disease, plasma cholesterol, blood pressure, and smoking habit, account for only a modest proportion of deaths from the disease, ${ }^{12}$ and other unknown factors may have an important role. Several population based studies have shown close correlations between cardiovascular risk factors such as hypertension, hyperlipidaemia, and obesity with glucose intolerance and hyperinsulinaemia. ${ }^{3-6}$ Hyper- insulinaemia has been investigated as a risk factor for ischaemic heart disease in at least three longitudinal studies, ${ }^{7-9}$ but the interpretation of the results from these studies remains controversial. ${ }^{10} \mathrm{~A}$ recent editorial stressed the need for further prospective data in this area. ${ }^{11}$

We have already reported the association between hyperinsulinaemia and pre-existing ischaemic heart disease and other cardiovascular risk factors. ${ }^{12}$ In the present report we examine the ability of insulin to predict future ischaemic heart disease in non-diabetic men from the Caerphilly cohort followed up for five years, taking account of other factors that may confound the relation.

Subjects and methods STUDY POPULATION

A $100 \%$ sample of men was selected from within a defined area (total population, 40000 ) of Caerphilly town and several surrounding villages. They were aged between 45 and 59 when first examined. A total of 2512 men were seen- $89 \%$ of the 2818 found to be eligible.

\section{SURVEY METHODS AND FOLLOW UP} PROCEDURE

At recruitment the men attended an afternoon or evening clinic at which a standard medical and smoking history was obtained; the London School of Hygiene and Tropical Medicine chest pain questionnaire was given; height, weight and blood pressure were measured; and a 12 lead electrocardiogram was recorded. They then returned, after an overnight fast, to an early morning clinic where a blood sample was taken. Fasting samples were obtained from 2368 men. Full details of the population sample and clinic procedures have been reported previously. ${ }^{13}$

This paper reports the first follow-up of the men, at a nearly constant interval of 61 months $(\mathrm{SD}=5)$. At follow up the chest pain questionnaire was given again, and a second electrocardiogram recorded. The chest pain questionnaire was extended to include questions about admission to hospital for severe chest pain. Those, together with hospital activity analysis notifications of admissions coded 410-414 by the International Classification of Diseases (ninth revision) were used as the basis for a search of hospital notes for events that satisfied the World Health Organisation criteria for definite acute myocardial infarction. For men who had died 
before the follow up, a copy of the death certificate was automatically received from the NHS central registry. From the information, three categories of events indicative of incident ischaemic heart disease were defined, ${ }^{14}$ namely, death from ischaemic heart disease (cause of death coded to ischaemic heart disease 410-414), clinical non-fatal myocardial infarction (an event satisfying the World Health Organisation criteria), and electrocardiographic myocardial infarction (appearance of major or moderate $Q$ or $Q S$ waves, Minnesota codes 1-1-1 through to $1-2-5$ or 1-2-7 on the follow up electrocardiogram when there were no $Q$ or $Q S$ waves, Minnesota codes 1-1-any, 1-2-any or 1-3-any, on the electrocardiogram at recruitment).

\section{LABORATORY METHODS}

Fasting samples were obtained from up to 30 subjects at a morning clinic. Venous samples were collected by the use of a $19 \mathrm{G}$ cannula with minimum stasis. Lipid samples were taken into edeitic acid; and for insulin assays serum was used.

Total cholesterol ${ }^{15}$ and total triglyceride ${ }^{16}$ were measured with commercially available enzymatic colorimetric methods. Glucose determinations were made on plasma samples with a Beckman Astra 8 analyser by the oxygen rate method. ${ }^{17}$ Total immunoreactive insulin was measured with a radioimmunoassay based on a double antibody for insulin. ${ }^{18}$ All samples for hormone analysis were frozen at $-20^{\circ} \mathrm{C}$ before assay. Samples were assayed within four months of collection.

\section{STATISTICAL METHODS}

Fasting blood samples were not taken from 144 men. Diabetic subjects, 60 men with a self-reported history of diabetes, and prediabetic subjects, 21 men with a fasting blood glucose concentration of $\geqslant 8 \mathrm{mmol} / 1$ were excluded from subsequent analyses. This left 2287 men available for the analysis. Insulin was measured in 2022 of these men as serum was not collected at the beginning of the survey. Univariate analyses are based on these numbers. Multivariate analyses (multiple logistic regression and multiple regression) involving smoking, blood pressure, body mass index, and total triglyceride are based on between 40 and 89 fewer men depending on which variables are included.

The distributions for insulin and triglyceride were log-normal, and individual values were transformed to natural logarithms.

Table 1 Incidence of ischaemic heart disease (IHD) by fifths of the distribution of insulin

\begin{tabular}{llll}
\hline & & \multicolumn{2}{l}{ Insulin } \\
\cline { 3 - 4 } $\begin{array}{l}\text { Fifths of } \\
\text { distribution }\end{array}$ & No & $\begin{array}{l}\text { Incident } \\
\text { IHD (\%) }\end{array}$ & $\begin{array}{l}\text { Relative* } \\
\text { odds }\end{array}$ \\
\hline 1 (lowest) & 378 & $17(4 \cdot 5)$ & 1.00 \\
2 & 408 & $18(4 \cdot 4)$ & 1.02 \\
3 & 405 & $21(5 \cdot 2)$ & 1.19 \\
4 & 415 & $25(6.0)$ & 1.43 \\
5 (highest) & 416 & $32(7 \cdot 7)$ & 1.87 \\
\hline (1) & &
\end{tabular}

Table 2 Standardised relative odds for ischaemic heart disease (IHD) after adjusting for confounding factors in 1933 men

\begin{tabular}{lll}
\hline Adjusted for & $\begin{array}{l}\text { Standardised } \\
\text { relative odds }\end{array}$ & $t$ Value \\
\hline Age & 1.20 & $2.05^{\star}$ \\
Age + log triglyceride & 1.12 & 1.10 \\
Age + pre-existing IHD & 1.07 & 0.64 \\
Age + body mass index & 1.04 & 0.36 \\
\hline${ }^{\star} \mathrm{p}<0.05$. & &
\end{tabular}

In the logistic regression analyses insulin concentrations were treated in two ways. Firstly, their distributions were divided into equal fifths, and the results presented as the odds of major incident heart disease in each fifth relative to the lowest fifth (table 1). Secondly, insulin was entered as a continuous variable and the results presented as a standardised relative odds, defined as the proportionate change in odds for a one SD change in $\log$ (insulin) (table 2).

\section{Results}

INCIDENCE OF ISCHAEMIC HEART DISEASE

A total of 113 events indicating ischaemic heart disease occurred during the period of follow up (average five years) among the 2022 men for whom insulin values were available. The average annual incidence was $1 \cdot 1 \% ; 50 \%$ of the events were fatal, $39 \%$ were clinical non-fatal myocardial infarction, and $11 \%$ were defined by electrocardiogram.

\section{UNIVARIATE ANALYSES}

Table 3 shows the geometric mean values of fasting serum insulin at recruitment, by ischaemic heart disease state at follow up. Mean log [insulin] was higher by $0.138(95 \%$ confidence interval $(95 \% \mathrm{CI})-0.004$ to $0 \cdot 280$ ) in men who subsequently had major ischaemic heart disease. This difference did not quite reach the conventional level of significance, with $p=0 \cdot 06$. This difference in mean $\log$ [insulin] corresponds to a ratio of the geometric means of $1 \cdot 15$, with $95 \% \mathrm{CI}$ 1.00 to 1.32 .

Table 1 shows the incidence of ischaemic heart disease by fifths of the distribution of insulin and the age adjusted relative odds. The relative odds increased steadily with increasing insulin concentration, to a value of 1.87 in the top $20 \%$ of the insulin distribution. This trend is significant $(p=0 \cdot 04)$.

Fasting serum insulin was positively associated with total cholesterol $(r=0 \cdot 13)$, triglycerides $(r=0.48)$, diastolic $(r=0.17)$ and systolic $(r=0 \cdot 13)$ blood pressure, body mass

Table 3 Mean (95\% range) concentration of serum insulin at recruitment in men with and without incident ischaemic heart disease (IHD) at follow up

\begin{tabular}{lll}
\hline IHD at follow up & No & Insulin $(m U / l)^{*}$ \\
\hline Present & 113 & $6.53(1.5$ to $28 \cdot 2)$ \\
Absent & 1909 & $5.69(1.3$ to $24 \cdot 8)$ \\
\hline
\end{tabular}

* Mean values are antilogs of the men on the log scale (geometric mean). 
Table 4 Mean difference in log [insulin] between men who developed ischaemic heart disease (IHD) and those who did not: effect of successive adjustment for confounding factors

\begin{tabular}{ll}
\hline Adjusted for & $\begin{array}{l}\text { Mean difference in } \\
\text { log [insulin] } \\
(95 \% \mathrm{CI})\end{array}$ \\
\hline Age & $0.15^{\star}(0.01$ to 0.30$)$ \\
Age + log triglyceride & $0.08(-0.05$ to 0.21$)$ \\
Age + pre-existing IHD & $0.04(-0.09$ to 0.17$)$ \\
Age + body mass index & $0.02(-0.10$ to 0.15$)$ \\
\hline${ }^{\star} \mathrm{p}<0.05$ &
\end{tabular}

index $(r=0 \cdot 39)$, and fibrinogen $(0 \cdot 13)$. It was negatively associated with high density lipoprotein cholesterol $(r=-0 \cdot 16)$ and with smoking. Current smokers had geometric mean insulin concentrations of $5.40 \mathrm{mIU} / 1$ compared with mean concentrations of $6 \cdot 14$ among ex-smokers and $6 \cdot 28$ among men who had never smoked.

The strongest associations were with triglycerides and body mass index. The associations with blood pressure seemed to arise largely because both insulin and blood pressure were associated with body mass index. The partial correlation coefficient between diastolic pressure and insulin on adjustment for body mass index was only $0 \cdot 07$. Similarly, the associations between total and high density lipoprotein cholesterol and insulin were secondary to the association of all three with triglycerides. Therefore in the multivariate analysis, triglycerides and body mass index, together with evidence of ischaemic heart disease at recruitment, were considered as the most likely confounding factors of the relation between insulin and incident ischaemic heart disease.

\section{MULTIVARIATE ANALYSES}

For insulin the age adjusted, standardised relative odds for ischaemic heart disease were $1.20(p=0.04)$ with a $95 \%$ CI from 1.01 to $1 \cdot 44$.

Table 2 shows the effect of adjusting the standardised relative odds for ischaemic heart disease successively for triglycerides, body mass index, and pre-existing ischaemic heart disease with the multiple logistic regression. The addition of triglyceride removed almost half of the insulin effect and the further addition of pre-existing ischaemic heart disease removed about one half of the remaining effect. This was further reduced by the addition of body mass index.

This analysis was confirmed by a multiple regression (covariance) analysis with log [insulin] as the dependent variable, in which the mean difference in log [insulin] between men who developed ischaemic heart disease and those who did not was calculated. Table 4 shows the changes in the mean difference as successive confounding factors were added to the model. The results confirmed that successive adjustment for confounding variables, and for triglycerides in particular, almost eliminated the association between insulin concentrations and subsequent ischaemic heart disease:

\section{Discussion}

In a five year follow up of middle aged men, those who had developed ischaemic heart disease were found to have significantly higher concentrations of serum insulin measured at recruitment than those in men who had not developed ischaemic heart disease. This relation also showed incremental increases in risk of ischaemic heart disease when subjects were stratified by fifths of their recruitment concentration of insulin. In two multivariate analyses in which potentially confounding factors were taken into account the relation was found to be mainly explained by plasma triglyceride concentration, pre-existing ischaemic heart disease, and body mass index. Plasma triglyceride was found to be a strong and independent predictor for ischaemic heart disease in the Caerphilly and Speedwell study populations, ${ }^{19}$ although other prospective studies have not consistently identified triglyceride as a major risk factor. ${ }^{20}$

Two $^{78}$ out of three ${ }^{9}$ prospective studies showed that insulin concentrations were univariately predictive of ischaemic heart disease and others have proposed mechanisms by which hyperinsulinaemia might be atherogenic $^{21}$ and associated with hypertension. ${ }^{22}$ In multivariate analysis, fasting insulin concentration could not be shown to be an independent predictor for ischaemic heart disease in either the Helsinki ${ }^{7}$ or Paris $^{8}$ studies. In the Helsinki study there was some suggestion of an independent role for insulin $(p=0.12)$ after adjustment for confounding factors including both triglycerides and body mass index. The Paris study did not include either triglycerides or body mass index among its confounding factors. In our study the effect of insulin almost entirely disappeared on adjusting for these two factors. None of these studies are large. The Helsinki ${ }^{7}$ study was based on 63 cases and the Paris ${ }^{8}$ study on 174 cases of incident ischaemic heart disease, and our study had 113 cases.

Several studies have noted a clustering of risk factors around insulin resistance ${ }^{34}$; these factors generally include hyperlipidaemia (usually triglyceride), hypertension, and obesity. Some studies have attempted to examine the interrelations of these factors. ${ }^{23} 24$ In metabolic $^{25}$ and epidemiological studies ${ }^{26}$ hyperinsulinaemia or insulin resistance is associated with hypertriglyceridaemia and increased hepatic triglyceride secretion. In a recent experimental study reductions in serum insulin concentrations seemed to be secondary to reductions in triglyceride concentrations induced by gemfibrozil. ${ }^{27}$

Measurement of insulin in human plasma and serum has been commonplace since its first description some 30 years ago by Berson and Yalow. ${ }^{28}$ It has, however, only recently been fully appreciated that a variable fraction of total immunoreactive insulin is composed of moieties possessing insulin like immunoreactivity other than insulin itself. ${ }^{29-31}$ These are mostly, if not entirely, proinsulin and its diverse cleavage products, which differ appreciably in their biological properties both from 
native insulin and from each other. The contribution made to total immunoreactive insulin by proinsulin and its cleavage products is greater in patients with type II diabetes, ${ }^{31}$ insulinoma $\mathrm{a}^{3233}$ and possibly other disorders of lipid and carbohydrate metabolism, than in healthy, age matched controls.

Without exception all previous studies of the relation between circulating "insulin" and the incidence or prevalence of ischaemic heart disease including this one have used assays that measure total immunoreactive insulin rather than native insulin itself. In the present analysis, diabetic subjects and subjects with fasting glucose concentrations of $\geqslant 8.0 \mathrm{mmol} / 1$ are excluded, and it is only in such subjects that proinsulin and its cleavage products may constitute a significant proportion of total immunoreactive insulin. Any bias introduced by inaccurate assessment of atherogenic proinsulin cleavage products is likely therefore to be small.

Some authors have suggested that fasting insulin concentrations are not a reliable index of insulin secretion. ${ }^{34}$ Thus the non-fasting state may be more relevant to the study of insulin and ischaemic heart disease but in epidemiological studies this is difficult to achieve in a standard, relevant manner. More experimental data on the response of insulin secretion to particular nutrients may be helpful.

In our study fasting plasma triglyceride was the major independent lipid marker of risk for the development of subsequent ischaemic heart disease. ${ }^{19}$ Further research on the mechanism of the association between triglyceride and ischaemic heart disease is particularly required.

1 Heller RF, Chinn S, Tunstall Pedoe HD, Rose G. How well can we predict coronary heart disease? Findings in the United Kingdom Heart Disease Prevention Project. BMF 1984;228:1409-11.

2 Werkö $\mathrm{L}$. The enigma of coronary heart disease and its prevention. Acta Med Scand 1987;221:323-33.

3 Modan M, Halkin F, Almog S, Lusky A, Eskol A, Shefi M, et al. Hyperinsulinemia-A link between hypertension, obesity and glucose intolerance. $\mathcal{f}$ Clin Invest 1985;75: obesity and

4 Ferrannini E, Haffner SM, Mitchell BD, Stern MP. Hyperinsulinemia: the key feature of a cardiovascular and metabolic syndrome. Diabetologia 1991;34:416-22.

5 Skarfors ET, Lithell HO, Selinus I. Risk factors for the development of hypertension: a 10 year longitudinal study in middle-aged men. $₹$ Hypertens 1991;9:217-23.

6 Rönnemaa T, Laakso M, Pyörälä K, Kallio V, Puukka P. Heart disease in non-insulin-dependent diabetic patients and nondiabetic subjects. Arterioscler Thromb 1991; and $11: 80-90$.

7 Pyörälä K, Savolainen E, Kaukolas S, Haapakoski J. Plasma insulin as coronary heart disease risk factor: relationship to other risk factors and predictive value during $9 \frac{1}{2}$ year follow-up of the Helsinki policemen study population. Acta Med Scand 1985;701(suppl):38-52.

8 Fontbone A, Charles MA, Thibult N, Richard JL, Claude $\mathrm{JR}$, Warnet JM, et al. Hyperinsulinemia as a predictor of coronary heart disease mortality in a healthy population: The Paris Prospective Study, 15 year follow-up. Diabetologia 1991;34:356-61.

9 Cullen K, Stenhouse NS, Wearne KL, Welborn TA. Multiple regression analyses of risk factors for cardiovascular disease and cancer mortality in Busselton, Western
Australia-13 year study. $\mathcal{F}$ Chron Dis 1983;36:371-7

10 Jarret RJ. Is insulin atherogenic? Diabetologia 1988;31: 71-5.

11 Savage PJ, Saad MF. Insulin and atherosclerosis: villain, accomplice, or innocent bystander? Br Heart $\mathcal{f} 1993$; 69:473-5.

12 Litchenstein MJ, Yarnell JWG, Elwood PC, Beswick AD, Sweetnam PM, Marks V, et al. Sex hormones, insulin,
lipids and prevalent ischaemic heart disease. $A m \mathcal{F}$ Epidemiol 1987;126:647-57.

13 The Caerphilly and Speedwell Collaborative Group. Caerphilly and Speedwell Collaborative Heart Disease 14 Yarnell JWG, Baker IA, Sweetnam PM, Bainton D, O'Brien JR, Whitehead PJ, et al. Fibrinogen, viscosity and white cell count are major risk factors for ischaemic heart disease. The Caerphilly and Speedwell collaborative heart disease studies. Circulation 1991;83:836-44.

15 Steele BW, Koehler DF, Kuba K, Azar MM. An enzymatic approach to lipoprotein quantification. Am $\mathcal{f}$ Clin Pathol 1980;73:75-8.

16 Buccolo G, David H. Quantitative determination of serum triglycerides by the use of enzymes. Clin Chem 1973;19: 476-82

17 Kadish AH, Little RL, Sternberg JC. A new and rapid method for the determination of glucose by measurement of rate of oxygen consumption. Clin Chem 1968; 14:116-31.

18 Starr JI, Rubenstein AH. Insulin, proinsulin and C-peptide. In: Jaffe BM, Behrman HR, eds. Methods of hormone radioimmunoassay. 1st ed. New York: Academic mone radioims, 1974.

19 Bainton D, Miller NE, Bolton $\mathrm{CH}$, Yarnell JWG Sweetnam PM, Baker IA, et al. Plasma triglyceride and high density lipoprotein cholesterol as predictors of ischaemic heart disease in British men. Br Heart $\mathcal{F} 1992$; 68:60-6.

20 Austin MA. Plasma triglyceride as a risk factor for coronary heart disease: the epidemiologic evidence and beyond. Am $\mathcal{F}$ Epidemiol 1989;129:249-59.

21 Stout RW. Insulin and atheroma-an update. Lancet 1987;i:1077-9.

22 Ferrannini E, Buzzigoli G, Bonadondna R, Giorico MA, Oleggini $M$, Grazidei $L$, et al. Insulin resistance in essenOleggini M, Grazidei L, et al. Insulin resistance in
tial hypertension. $N$ Engl $₹$ Med 1987;317:350-7.

23 Cambien F, Warner JM, Eschwege E, Jacqueson A, Richard JL, Rosselin G. Body mass, blood pressure, glucose and lipids: Does plasma insulin explain their relationship? Arteriosclerosis 1987;7:197-202.

24 Laws A, King AC, Haskell WL, Reaven GM. Relation of fasting plasma insulin concentration to high density lipoprotein cholesterol and triglyceride concentrations in men. Arterioscler Thromb 1991;11:1636-42.

25 Tobey EA, Greenfield M, Kraemer F, Reaven GM. Relationship of insulin resistance, insulin secretions, very low density lipoprotein kinetics, and plasma triglyceride low density lipoprotein kinetics, and plasma triglyceride
levels in normotriclyceridaemic men. Metabolism 1981; levels in norm $30: 165-71$.

26 Orchard TJ, Becker DJ, Bates M, Kuller LH, Drash AL. Plasma insulin and lipoprotein concentrations: an atherogenic association? $A m$ f Epidemiol 1983;118: 326-7.

27 Steiner G. Altering triglyceride concentrations changes insulin-glucose relationships in hypertriglyceridemic patients: double-blind study with gemfibrozil with implications for atherosclerosis. Diabetes Care 1991;14: cations fo77-81.

28 Berson SA, Yalow RS. Plasma insulin in man [editorial]

Am $\mathcal{F}$ Med 1960;29:1.
29 Temple RC, Carrington CA, Luzio SD, Owens DR, Schneider AE, Sobey WJ, et al. Insulin deficiency in non-insulin-dependent diabetes. Lancet 1989;i:293-5.

30 Temple RC, Clark PMS, Nagi DK, Schneider AE, Yudkin JS, Hales CN. Radioimmunoassay may overestimate insulin in non-insulin-dependent diabetics. Clin Endocrinol 1990;32:689-93.

31 Nagi DK, Hendra TJ, Ryle AJ, Cooper TM, Temple RC, Clark PM, et al. The relationships of concentrations of insulin, intact proinsulin and 32-33 split proinsulin with cardiovascular risk factors in type 2 (non-insulin-depencardiovascular risk factors in type 2 (non-insulin-depen-
dent) diabetic subjects. Diabetologia 1990;33:532-7.

32 Cohen RM, Given BD, Licinio-paixao J, Provow SA, Rue $\mathrm{PA}$, Frank BH, et al. Proinsulin radioimmunoassay in the evaluation of insulinomas and familial hyperproinsulinemia. Metabolism 1986;35:1137-46.

33 Marks V, Teale JD, Hampton SM. Proinsulin assays in insulinomas. In: Andreani D, Lefebore PJ, Marks V, Tamburrano G, eds. Recent advances in hypoglycemia. New York: Raven Press, 1992:145-59.

34 Garcia-Webb P, Bonser AM, Whiting D, Masarei JRL. Insulin resistance-a risk factor for coronary hear disease? Scand $¥$ Clin Lab Invest 1983;43:677-85. 